NBER WORKING PAPER SERIES

\title{
WHEN KNOWLEDGE IS NOT ENOUGH: HIV/AIDS INFORMATION AND RISKY BEHAVIOR IN BOTSWANA
}

\author{
Taryn Dinkelman \\ James Levinsohn \\ Rolang Majelantle \\ Working Paper 12418 \\ http://www.nber.org/papers/w12418
NATIONAL BUREAU OF ECONOMIC RESEARCH
1050 Massachusetts Avenue
Cambridge, MA 02138
July 2006

Levinsohn gratefully acknowledges support from the National Institute for Child Health and Human Development (NICHD). Zoe McLaren, Jee-Yeon Kim, and Stella Binkevich provided exemplary research assistance. The authors are grateful to Ms. Anna Majelantle, Director of the Central Statistics Office of the Ministry of Finance and Development Planning of Botswana for data access. Thanks to Rachel Snow and Nicoli Natrass for helpful comments. The views expressed herein are those of the author(s) and do not necessarily reflect the views of the National Bureau of Economic Research.

(C2006 by Taryn Dinkelman, James Levinsohn and Rolang Majelantle. All rights reserved. Short sections of text, not to exceed two paragraphs, may be quoted without explicit permission provided that full credit, including (C) notice, is given to the source. 
When Knowledge is not Enough: HIV/AIDS Information and Risky Behavior in Botswana Taryn Dinkelman, James Levinsohn and Rolang Majelantle

NBER Working Paper No. 12418

July 2006

JEL No. I18, O10

\begin{abstract}
The spread of the HIV/AIDS epidemic is still fueled by ignorance in many parts of the world. Filling in knowledge gaps, particularly between men and women, is considered key to preventing future infections and to reducing female vulnerabilities to the disease. However, such knowledge is arguably only a necessary condition for targeting these objectives. In this paper, we describe the extent to which HIV/AIDS knowledge is correlated with less risky sexual behavior. We ask: even when there are no substantial knowledge gaps between men and women, do we still observe sex-specific differentials in sexual behavior that would increase vulnerability to infection? We use data from two recent household surveys in Botswana to address this question. We show that even when men and women have very similar types of knowledge, they have different probabilities of reporting safe sex. Our findings are consistent with the existence of non-informational barriers to behavioral change, some of which appear to be sex-specific. The descriptive exercise in this paper suggests that it may be overly optimistic to hope for reductions in risky behavior through the channel of HIV-information provision alone.
\end{abstract}

James A. Levinsohn

Department of Economics

University of Michigan

Ann Arbor, MI 48109-1220

and NBER

james1@umich.edu 


\title{
When knowledge is not enough: HIV/AIDS information and risky behavior in Botswana
}

\author{
Taryn Dinkelman \\ James Levinsohn * \\ Department of Economics \\ Ford School of Public Policy \\ University of Michigan \\ University of Michigan and NBER \\ Rolang Majelantle \\ Department of Population Studies \\ University of Botswana
}

July 24,2006

\section{Introduction}

In many parts of the world, the spread of the HIV epidemic is still fueled by ignorance. This lack of knowledge is often unequally distributed in the population. A recent UNAIDS AIDS Update Report (2005) notes that: "Data from 35 of the 48 countries in sub-Saharan Africa show that, on average, young men were $20 \%$ more likely to have correct knowledge about HIV than young women." ${ }^{1}$ Filling in this knowledge gap is considered key in the fight against HIV and in efforts to reduce the vulnerability of women and girls.

Despite the consensus that information and education about the disease are a critical part of any HIV/AIDS intervention (See discussion in chapter 2 of UNAIDS and UNIFEM (2004).), it is not clear what effects to expect from such information campaigns, particularly for women. Knowledge is arguably only a necessary condition for reducing the rate of new infections. The public health literature has often highlighted the role of non-biological factors that may increase HIV transmis-

\footnotetext{
${ }^{*}$ Levinsohn gratefully acknowledges support from the National Institute for Child Health and Human Development (NICHD). Zoe McLaren, Jee-Yeon Kim, and Stella Binkevich provided exemplary research assistance. The authors are grateful to Ms. Anna Majelantle, Director of the Central Statistics Office of the Ministry of Finance and Development Planning of Botswana for data access. Thanks to Rachel Snow and Nicoli Natrass for helpful comments.

${ }^{1} \mathrm{See}$ UNAIDS/WHO AIDS epidemic update: December 2005 available at: http://www.unaids.org/epi/2005/doc/EPIupdate2005_html_en/epi05_05_en.htm. (Accessed June 12, 2006.)
} 
sion rates particularly for women: MacPhail, Williams and Campbell (2002) discuss social factors contributing to heightened vulnerability of young women, and Farmer (1996) discusses some of the structural barriers of poverty which prevent reductions in risky behavior for women. UNAIDS and UNIFEM (2004) notes that differences in bargaining power in high poverty, low education and high gender inequality environments mean that insufficient knowledge may not be the only barrier to protecting oneself.

In this paper, we use new data from a national household survey in Botswana to describe what happens when men and women actually do have the same information about HIV/AIDS. First, we document how Botswana is unusual compared to many other African countries. The country has one of the most advanced HIV epidemics on the continent. We also show that HIV/AIDS awareness is high in Botswana, and the distribution of information is relatively equal across men and women. For some types of information, women are even more likely to know correct facts. Part of this is certainly the result of well-established national information, education and communication (IEC) policies, on which we provide details below. Second, we exploit this unique context of equal information to ask: do men and women still report differences in behaviors associated with lower HIV transmission risks? We use simple logit models to describe how information, demographics and risk profiles of partners relate to the probability of using condoms, and how this relationship differs by sex. We do not focus on differences in HIV prevalence across sexes in this paper since current prevalence rates are a function of past behaviors. Instead, we concentrate on the relationship between current levels of HIV information and current behaviors that may contribute to future HIV prevalence rates.

We cannot measure the causal impact of information on behavior using the solely cross-sectional data available in Botswana. This is because we cannot observe sex-specific changes in sexual behaviors after an exogenous change in HIV-relevant information, nor can we argue that the national IEC campaigns randomly reached some segments of the population by 2004 and not others. However, cross-sectional correlations still provide insights into possible barriers to behavioral change in a country in which HIV knowledge is widespread and not significantly different between men and women. The results from our logit models of condom use indicate that even when men and women have very similar types of knowledge, they do not have the same probabilities of reporting protective behaviors. Much of the gap appears to be made up by sex differences in the likelihood of condom use with more risky partners, conditional on HIV information. Furthermore, when encounters involve alcohol, condom use is significantly less likely for both men and women conditional on knowing how HIV is transmitted and protected against. These findings are consistent with the existence of non-informational barriers to behavioral change, some of which appear to be sex-specific. 
Overall, our descriptive analysis suggests that public health information campaigns that are successful at reaching the masses may alone not be successful in combatting the disease. We conclude that more detailed work is needed to understand why HIV knowledge is not protection, and that this work would benefit from focussing on (1) how men and women are differently able to negotiate condom use with more risky partners, and (2) the relationship between alcohol use and risky sexual behavior.

The paper proceeds as follows. Section 2 provides some broad background on HIV/AIDS knowledge in Africa and Section 3 describes the data that we use. Section 4 outlines the Botswana information and education campaigns and presents descriptive statistics of the sample. Section 5 describes the HIV knowledge of different sub-groups in Botswana in 2004 and relates this knowledge to prior information gaps measured in a 2001 survey as well as to levels of HIV knowledge in other African countries. Section 6 contains the simple logit models measuring the correlations between information and reported sexual behavior. Section 7 concludes.

\section{$2 \mathrm{HIV} / \mathrm{AIDS}$ knowledge in Africa}

Many public health studies have tried to measure the causal effect of HIV information on risk behaviors. These studies generally compare reported behaviors from groups of people who are exposed to HIV information to those who are not. For the most part, these treatment-control studies are conducted on small community-based samples, and focus on face-to-face provision of information or counseling. ${ }^{2}$ There are other data more suited to describing the national distribution of HIV knowledge, but less able to answer the causal question of how does information change behavior.

Much of what is known about the extent of HIV/AIDS knowledge at the population level in Africa comes from analysis of several nationally representative Demographic Health Surveys (DHS) ${ }^{3}$ Although the DHS are designed to capture fertility and family planning data, more recent waves include questions on HIV-related knowledge and behaviors. Several robust patterns about HIV knowledge emerge from these data. These include: i) Men tend to have better knowledge of HIV

\footnotetext{
${ }^{2}$ For example, see Kamb, Fishbein, Douglas and et al (1998) and Coates, Counseling and Group (2000). In the Kamb, Fishbein, Douglas and et al paper, 5758 individuals who approached STD clinics for testing were randomly assigned to interactive HIV/STD counseling or didactic prevention messages. Behavioral questionnaires and STD tests were administered at baseline and 4 subsequent rounds. In the Coates, Counseling and Group paper, 3706 eligible study participants were solicited through the local media and directly by the staff associated with the project and randomly assigned to VCT or more general health information. Reports on sexual behavior as well as HIV tests were taken at baseline and follow-up.

${ }^{3}$ See Gersovitz (2005)and Glick and Sahn (2005) for two recent surveys of DHS data from a set of East and West African countries. The only southern African country included in the analysis is Zambia.
} 
prevention methods than women; ii) Urban residents tend to have better knowledge about HIV than do their rural counterparts, but this gap has often fallen (slightly) over time; iii) HIV knowledge is strongly positively correlated with education; and iv) Older cohorts tend to have better information about the disease than do the under-20 cohorts. One explanation offered for these patterns is that they are the result of different sub-samples having differential costs of acquiring HIV-related information. For example, the opportunity cost of listening to the radio is lower for the stay-athome elderly while urban residents may be more readily exposed to billboards and to condoms in many public buildings. However, it is not altogether clear from these studies why, conditional on urban area, age and education levels, women are often still less likely to have HIV information than men.

While general awareness of HIV/AIDS appears almost universal in all of the countries surveyed in the $\mathrm{DHS}^{4}$, there is evidence of very low levels of understanding of some key HIV prevention methods. Table 1 reproduces some of the data on HIV knowledge from the DHS for a range of African countries. ${ }^{5}$ Only 70 percent of urban women of childbearing age in Burkina Faso in 2003 report knowing that using condoms can reduce the risk of infection. Corresponding percentages for Kenya (2003) are 69 percent and for Nigeria (2003) are 58 percent. Knowledge is somewhat higher for urban women in Tanzania (72 percent in 1999) and Zambia (80 percent in 2001). Knowledge of mother to child transmission is very low in Nigeria and Burkina Faso. The one key point to notice in that table is that for most of the columns, men are more likely to report correct knowledge than women- in some cases this gap is 20 percentage points.

In most of the countries surveyed in this literature, the HIV/AIDS epidemic is far less prevalent than it is in Botswana. Estimated prevalence for the population aged 15-49 in the relevant DHS is $1.8 \%$ for Burkina Faso, 2.2\% for Ghana, $7 \%$ in Tanzania and $15.6 \%$ in Zambia. Below, we describe how Botswana compares with these countries on HIV knowledge and knowledge gaps. In particular, columns (2) and (3) of table 1 will stand in contrast to the corresponding data we present on Botswana.

\section{The data}

We use data from two waves of the Botswana AIDS Impact Survey to examine information and behavior: BAIS-1 (2001) and BAIS-2 (2004). ${ }^{6}$ The sampling frame for BAIS-1 was the 1991

\footnotetext{
${ }^{4}$ In most countries, upwards of $70 \%$ of the DHS samples of adult women report that they have heard of HIV/AIDS.

${ }^{5}$ Summary statistics are taken from the MeasureDHS HIV/AIDS Survey Indicators Database at http://www.measuredhs.com. MeasureDHS is the organization that conducts all of the DHS, sometimes in collaboration with national governments.

${ }^{6} \mathrm{~A}$ third wave is planned for 2009 .
} 
Botswana Census and the sampling frame for BAIS-2 was the Botswana 2001 Census. Each wave was designed to be nationally representative. Since the samples were re-drawn for each survey, BAIS-1 and BAIS-2 constitute two independent cross-sections of data.

BAIS-1 was conducted by the Botswana government's Central Statistics Office between January 18 and March 5, 2001. Data were collected at three levels: from individuals, from households and from community leaders. 7 BAIS-1 was designed to provide a benchmark against which future levels of knowledge and reported behaviors could be measured.

This survey interviewed 7751 individuals in 1782 households. Household-level questionnaires collected demographic details about each household member and information on how households have been affected by HIV/AIDS (illnesses and deaths within the household). The individual-level questionnaire was only administered to consenting individuals aged 10 to 64 years of age. Due to the sensitive nature of the survey, individuals within a household answered the questionnaire privately.

In the individual survey, respondents were asked questions about their own sexual histories, details about their sexual partners, as well as questions about their knowledge of the transmission methods of HIV/AIDS, modes of protection against the disease and attitudes towards people living with HIV/AIDS. The set of questions regarding the three most recent sexual partners in the last 12 months are particularly detailed, and enable us to differentiate between more and less risky types of partnerships when we analyze condom use below. ${ }^{8}$

In 2004, BAIS-2 was collected. The survey was in the field from February 2004 through August 2004. As with BAIS-1, there were individual-level, household-level, and community-level survey instruments. Although the individual-level and household-level survey instruments in BAIS-2 are not identical to those in BAIS-1, there is a great deal of overlap.

One difference between the two samples is their size. Having treated BAIS-1 as a first-pass, BAIS-2 was more ambitious in scope and size. BAIS-2 surveyed 28,500 individuals in 7594 households, out of a total population of under 2 million people. An HIV survey in the U.S. of comparable relative size would need to include over three and a half million respondents. In addition to a larger sample size, the list of questions asked was expanded beyond those in BAIS-1. We use both waves of BAIS to describe information gaps over time, but focus on BAIS-2 to analyze the correlation between information and behavior. ${ }^{9}$

\footnotetext{
${ }^{7}$ The purpose of the survey was to provide "information for assessing the HIV/AIDS intervention programs." Office(2001)

${ }^{8}$ The Appendix contains a list of the information and partnership questions that we used from each survey.

${ }^{9}$ We believe we are the first to use these data for research purposes. At this time (June 2006), neither data set is in the public domain.
} 


\section{Descriptive statistics and context}

Botswana is a country with the same landmass as France, but with a population less than one fifth of the Paris metropolitan area. The first case of HIV in this sparsely populated country was diagnosed in 1985, and by 2004, Botswana had the second highest rate of HIV prevalence for adults aged 15-49 in the world: 37.3\%. ${ }^{10}$ There are currently an estimated 350,000 people living with HIV/AIDS in Botswana.

Table 2 provides some context by presenting summary statistics for the entire sample in each wave. Survey means are weighted to be representative of the population in each year. ${ }^{11}$ Panel A uses the entire sample, while Panel B restricts samples to adults, defined here as individuals aged 20 years and older.

Botswana has a youthful population with an average age of around 25. More than 40 percent of the population is younger than 20 years old. ${ }^{12}$ Only about 8 percent of the population are 60 or older. Under $55 \%$ of respondents reside in urban areas, where 'urban' includes towns as small as 5,000 residents. Only about 10 percent of the population live in the capital city, Gaborone. Average household size declines rather substantially between BAIS-1 to BAIS-2.

The second panel of Table 2 restricts the sample to adults. By U.S. or African standards, marital arrangements in Botswana are striking. These marriage patterns are not new to the country (Cohen(1998)), and may interrelate with HIV transmission in important ways. The age at first marriage is fairly high at just above 26 years old. ${ }^{13}$ The age of first sex is considerably lower, at 18.9 and 18.4 years in each wave respectively. Slightly less than half of all adults are married or living together. The fraction who are divorced or separated is small (under $3 \%$ ) and over $7 \%$ of the adult population is widowed in both surveys. ${ }^{14}$ Fully 40 to 45 percent of adults have never married or cohabited. Some of this reflects the late age at first marriage and the youthful population. It is important to note, though, that many of those never married or living together may still be in stable relationships. In Botswana, the "visiting union" is common (and not a new phenomenon) and partners in a visiting union may have a reasonably stable relationship even though they do not

\footnotetext{
${ }^{10}$ See: http://www.unaids.org/EN/Geographical+Area/by+country/botswana.asp (accessed July, 2005) for details. Only tiny Swaziland has a higher estimated prevalence rate (38.3 percent) in all of Africa. For a more detailed examination of prevalence rates in Botswana and how they are computed (and mis-computed), see Levinsohn and $\operatorname{McCrary}(2006)$.

${ }^{11}$ Economic variables in the waves of BAIS are few. The most obvious such omission is any measure of income. There are no income measures in either wave of the BAIS.

${ }^{12}$ The only substantial change in the age structure of the BAIS-1 and BAIS-2 samples is the proportion of the population aged 10-19. That fraction falls slightly more than 3 percentage points. This is true for both the (reported) weighted and the unweighted samples.

${ }^{13}$ This mean is not significantly affected by selecting on the adult sample of over 20-year-olds.

${ }^{14}$ Although this percentage is smaller- around $2 \%$ - for the adult population between 20 and 50 years of age.
} 
live together. ${ }^{15}$

Education patterns show that 30 to 40 percent of adults report primary school ( 7 years of schooling) as the highest level of education obtained, about 45 percent report secondary school (12 years of schooling) as the highest level obtained and 15-20 percent report tertiary education. This is high by African standards- Botswana's relative wealth (largely the result of diamond mining taxes) has enabled it to provide substantial resources for human capital development of its citizens in the 1980s and 1990s. Despite the fact that Botswana is one of the richest countries in Africa, about one third of adults report that they cannot read easily.

These data highlight some of the challenges facing public education about HIV/AIDS in Botswana. Large parts of the population still reside in rural areas, creating logistical hurdles for some types of information disbursement. Information programs intensive in one-on-one contact- for example, Voluntary Counseling and Testing services- are likely to be significantly more costly than providing information through the mass media. With about one third of adults having only completed primary education, a significant fraction of the population is under-educated. The literacy rate reflects this and suggests that written education materials will probably not reach a significant fraction of the adult population. The large fraction of school age children highlights the potential payoff of integrating HIV education into schools, but some of these schools are also often geographically remote.

Botswana has mobilized many channels of information transmission throughout its IEC campaigns, which began in the late 1980s. The country currently spends more money per capita on HIV/AIDSrelated activities than any other country in southern Africa: about US $\$ 70$ per person was spent on core HIV/AIDS activities in 2002, of which about one fifth was allocated to education and prevention programs (Martin(2003).) Before the escalation of HIV-related mortality in Botswana, individuals referred to HIV/AIDS as the "radio disease", because the radio had been the main means of transmitting knowledge in the early stages of the information campaign Heald (2006).

The first wave of public information programs (1989-1997) emphasized three messages. Citizens were urged to abstain, to be faithful, and to "condomize." Abstinence was urged as the ultimate preventative action. For those who were sexually active, the advice was to have one partner only and to use condoms. Concurrently, pilot projects were initiated to prevent mother to child transmission (PMTCT). The three-pronged campaign and pilot PMTCT programs were well-established before the BAIS-1 survey, and were very similar to information interventions in other countries. ${ }^{16}$

In 2002, the second wave of programs commenced. These "Phase 2" programs included a scaling up of the PMTCT efforts, an expansion of the anti-retroviral (ARV) program, and a public ed-

\footnotetext{
${ }^{15}$ Cohen(1998) notes that in Botswana, "the institution of marriage has essentially disappeared."

${ }^{16}$ For a discussion of HIV/AIDS policy in Botswana, see (Heald (2006).)
} 
ucation campaign that moved beyond the initial three messages and focused more specifically on battling popular misinformation. Here, the emphasis was on de-stigmatizing HIV/AIDS, ${ }^{17}$ and on understanding HIV transmission channels. The national information campaign in this second wave continued to make great use of radio and incorporated audio-visual messages to overcome spatial and illiteracy barriers. For example, videos educating people about the importance of HIV status knowledge and ARV therapy were played in patient waiting rooms in hospitals and clinics across the country, ${ }^{18}$ while safe behaviors for HIV prevention were emphasized through a weekly national radio serial drama.

In the next section, we document how this multi-dimensional information and education campaign has reached different groups of people and make some comparisons over the short space of time between 2001 and 2004 .

\section{Information gaps}

To characterize information gaps in Botswana, we consider a subset of questions from the individuallevel surveys of BAIS covering general knowledge and awareness of HIV transmission and prevention methods. These questions are designed to uncover both how much people know about behaviors protective against HIV infection, and what their beliefs are about how HIV is transmitted. Note that not every individual in the household roster answered the individual questionnaire: only those between 10 and 64 who gave consent will have data for this part of the survey. Of those who were eligible (5225 in BAIS-1 and 19058 in BAIS-2), 78.6\% (77.7\%) answered the individual questionnaire in BAIS-1 (BAIS-2). 19

For all of the knowledge questions which we will examine, respondents could answer "Yes, No, Do not know". We reduce these three responses to only two in the following ways. When the correct answer to a question was "yes", we combine the "no" and "do not know" answers. When the correct answer to a question was "no", we combine the "yes" and "do not know" answers. The logic behind this approach is that from a policy perspective, "knowing" the wrong answer and simply not knowing the right answer have similar consequences. It is equally important to target information at an individual who "knows" that condoms cannot prevent HIV transmission as it is to target information at an individual who is not sure whether condoms can prevent HIV transmission.

\footnotetext{
${ }^{17}$ The President of Botswana became the first head of state to be publicly tested for HIV during this campaign Heald (2006).

${ }^{18}$ www.avert.org

${ }^{19}$ See Levinsohn and McCrary (2006) for more details on selection into the survey and into the HIV test that was administered as part of the survey.
} 
Table 3 presents sample means of responses to HIV knowledge questions by sex and area of residence, separately for BAIS-1 and BAIS-2. In contrast to Table 1, Table 3 indicates that large gaps in knowledge by sex do not seem to characterize the situation in Botswana. Column 1 reports the fraction of respondents who have ever heard of HIV in each of the two surveys. Among urban men and women, about $95 \%$ have heard of HIV. The figure falls to $90 \%$ for rural men. Overall, awareness is high. There are no significant changes from BAIS-1 to BAIS-2. This is consistent with the fact that the first wave of public education, which highlighted HIV awareness, was completed before BAIS-1.

Columns 2 and 3 focus on two of the key messages of the first wave of public education; they report on whether respondents knew that condoms reduce the risk of HIV transmission and whether respondents knew that monogamy reduces the risk. These questions were only asked of individuals who reported that they had heard of HIV before (column (1)). In contrast to many other African countries, the knowledge that condoms reduce transmission risks is very high among both women and men in urban and rural areas. By 2004, when BAIS-2 was conducted, between 80 and $90 \%$ of respondents (depending on gender and place of residence) knew that condoms reduce the risk of HIV transmission and that monogamy also reduces the risk.

Columns 4, 5, 6, and 7 deal with aspects of HIV that were the subject of the second phase of public education. These questions were also only answered by individuals who had heard of HIV before (column (1)). If the second phase of information and education campaigns had an impact on HIV knowledge, we should see this in positive changes in the proportion of people reporting correct answers to these questions.

Column 4 reports the results of whether the respondent knows that a person who appears healthy can in fact be HIV-positive. Given the long time lag between infection and development of symptoms that is characteristics of HIV/AIDS, this is a particularly important fact for people to know. The correct answer to the question is yes, hence respondents who replied "no" or "do not know" are grouped together. To fix ideas, $78 \%$ of urban women in BAIS-1 who had heard of HIV knew that an HIV-positive person can appear healthy, and the figure jumps to $85 \%$ in BAIS-2. The results for urban men are almost identical, while the corresponding figures for rural men and women are on the order of ten percentage points lower. These are exceptionally high levels of knowledge compared to responses to the same question in Nigeria (2003) (69\% of urban women answered correctly, $45 \%$ of rural women) and more along the lines of knowledge in Ghana (2003) (over $80 \%$ of men were informed and over $73 \%$ of women). ${ }^{20}$

Columns 5 and 6 in Table 3 report the proportion of people who know whether one can contract HIV by sharing a meal with an HIV-positive person, or by witchcraft. Here the figures reported are

\footnotetext{
${ }^{20}$ See Table 1
} 
the fraction that answered "yes" or "did not know" - that is, the fraction with incorrect information. Although the prevalence of misconceptions did fall between the two waves (more in urban than in rural areas), it is clear that tackling the misconceptions associated with HIV and witchcraft remains a challenge.

The last column reports the fraction of respondents who know that HIV can be transmitted from mother to child. While the urban-rural knowledge gap is again apparent, knowledge improved for all the cells between the two surveys. By BAIS-2, $91 \%$ of urban women and $87 \%$ of rural women knew about mother to child transmission.

To further consider how information differs across individuals of different ages and education categories, we estimate logit models for each HIV knowledge variable in BAIS-2. ${ }^{21}$ Table 4 contains the results of these models where we have controlled for gender, age cohort, years of education, and indicator variables set to one if the respondent was either married or cohabiting, working, and/or living in an urban area. Each covariate is interacted with a male dummy variable in order to test whether men in each group have significantly more or less information than women. Cell entries are the average of individual marginal effects computed from the logit model.

The results indicate that youngest cohorts (age 10-19, the base category) know the least about HIV. Since the median age at first sex for both boys and girls is 18.6 years (in table 2), this may be a cause for concern and suggests the potential for more school-based HIV education programs. Table 4 also highlights that individuals with more education are more likely to have better HIV knowledge- a finding that is echoed in most other studies using nationally representative data. For every question in the table, an extra year of education is significantly associated with a higher probability of a correct answer.

In contrast to almost every other study using African data, Table 4 indicates that the proportion of men and women who know the correct facts about the disease is almost the same, even within subgroups. Except for the first column, men are either equally likely to know the same information or somewhat less likely to know, conditional on other characteristics- for example, information about MTC transmission is less likely to be known by men. Men are also more likely to hold misconceptions about the disease: they are more likely to believe one could become HIV-positive by either sharing a meal with a seropositive person or by witchcraft. Looking at the set of male interaction terms, we can see that men and women do not appear to have significantly different probabilities of knowing the right information, even within subgroup. In column 1, an additional

\footnotetext{
${ }^{21}$ The same exercise for BAIS-1 yields qualitatively and quantitatively similar results. The largest differences were for columns (4), (5) and (6) in Table 3 - here, BAIS-1 individuals in urban areas were significantly more likely to report correct knowledge than individuals in rural areas. We also ran logit models on the pooled 2001 and 2004 data, with a full set of year interaction terms. We found few large improvements (or declines) in knowledge from BAIS-1 to BAIS-2.
} 
year of education is associated with a larger increase in the probability of having heard of HIV for women compared to men, but this difference is substantively small. In column 2, men between 20 and 39 years of age are significantly less likely to know that condoms can protect, compared to women of the same age, while in column 5, married men are less likely than married women to report that HIV/AIDS can be transmitted by sharing a meal with an HIV-positive person.

On the whole though, the fact that the male interaction terms are generally small and/or not significantly different from zero is remarkable- even in rural areas, the proportion of informed men and women appears to be the same. The test of the null hypothesis that all of the male interaction terms are jointly zero cannot be rejected for any of the information questions, except for the question in column (2), concerning condom protection. Here, it appears that men and women do have different probabilities of knowing the correct answer- most of this difference appears to be for men and women of the same age groups, where women have a higher likelihood of reporting correct knowledge.

The other striking fact to emerge from this table (and Table 3) is the overall awareness of HIV. By 2004 , about $96 \%$ of urban respondents and about $90 \%$ of rural respondents had heard of HIV, and $88 \%$ of respondents who had heard of HIV knew that condoms reduce risk. These figures include responses from individuals aged ten to 64. Compared to figures cited at the outset of the paper for other African countries, the data from the waves of the BAIS illustrate the broad success of Botswana's public health information and education campaign in getting information to people.

However, this success does not guarantee safer behavior change, which is one of the key variables of interest for policy makers. In the next section, we consider correlations between HIV/AIDS information and behavior. In particular, we look for evidence that individuals with the same types of information report different behaviors. If this is the case, then the data are consistent with a story in which HIV information is necessary but not sufficient for getting individuals to adopt less risky behaviors.

\section{The relationship between knowledge and behavior}

The behavior measures we consider here include the number of sex partners in the last 12 months and condom use at first and last sex with any of up to three recent partners. Table 5 reports means of these variables by sex for the sample in BAIS-2. The first three columns pertain to the full sample of all partnerships on which we have information, with the last three columns restricting the sample to those reporting only 1 partnership in the previous year. The table also present sex-specific means for variables that we will use in the logit models linking knowledge and behavior: these variables include all of the general HIV knowledge questions (specific questions about methods of MTCT 
are omitted) and a set of own and partner risk characteristics. Only individuals who report ever having had sex are included in the table. While the decision to have sex is also a margin along which individuals can adjust behavior in response to information about HIV/AIDS, we do not model sexual debut or secondary abstinence in this paper.

In the top panel of the table, summary measures of the set of risky behaviors are reported for individuals. ${ }^{22}$ As is usual in most surveys of this nature, men report about $25 \%$ higher average number of partners than women over the last year- about 0.3 of a partner. This difference is significant. Reported condom use at both first and last sex with a given partner is substantially more likely for men than for women: $62.5 \%$ of women and $70.8 \%$ of men report using a condom at last sex with a given partner.

There are three caveats regarding the number of partners variable. First, studies have documented systematic differences in the number of partners that women report compared to men. This occurs even in studies that include the entire sexual network of an area (Nnko, Boerma, Urassa, Mwaluko and Zaba (2004).) It is generally difficult to establish the form of the measurement error: whether women are under-reporting, or men are over-reporting, or both. Second, the modal number of recent sex partners in BAIS-2 is 1 , and it is just $12.3 \%$ of respondents who drive the average number of partners above 1 in Table $5 .{ }^{23}$ The observed data do not support the interpretation that many people have multiple partners. Third, having more partners is only significantly more risky behavior if condoms are not effectively used. For these reasons, we consider the link between knowledge and behavior by focusing on reported condom use rather than the number of partners in the rest of the paper. We look for associations between the level of HIV information a person has, their own and partner risk characteristics, and the likelihood of reporting condom use at last sex. 24

A caveat is also in order concerning our selected measure of risky behavior- (the lack of) condom usage. We interpret any sex without a condom as evidencing potentially risky behavior. Clearly, mutually faithful partnerships can involve no-risk encounters even when condoms are not used. Our approach to this ambiguity is to include a host of partnership characteristics controls in our logit models that allow us to compare condom use within similar types of partnerships, rather than across all partnerships.

The level of HIV knowledge in our sample, as well as several risk factors associated with greater vulnerability to HIV/AIDS, are also described in Table 5. Comparing men and women in the full

\footnotetext{
${ }^{22}$ That is, means are calculated over the individuals in the sample. At other points in the table (as indicated), averages are calculated over partnerships as opposed to individuals.

${ }^{23}$ The range of this variable for our sample of interest runs from 1 to $25.11 \%$ of the sample report 2 or 3 partners in the last year.

${ }^{24}$ We focus on last sex with a partner rather than first sex since recall is likely to be better with the former.
} 
and restricted sample, it appears that men and women are equally likely to know that condoms can reduce the risk of transmission and that having one partner who has no other partners can also protect. However, men are more likely to have heard HIV/AIDS information in the last 4 weeks, are somewhat more likely to know that a healthy person can be HIV-positive, and are less likely to report that they know HIV can be transmitted from MTC. Although these differences are significant, the size of the gap is relatively small for all of the variables. Looking back at Table 3, it is clear that we have a sub-sample of individuals who are, on average, better informed than the overall sample.

Turning to the risk characteristics, we see much larger, significant differences between men and women. Among men, $19.3 \%$ report that they have had multiple partners in the last year- this is more than double the proportion of women reporting multiple partners. All of the remaining means of risk variables are calculated over the partnership (not the individual) ${ }^{25}$ Over $60 \%$ of men report that one of their partners is a boyfriend or girlfriend who is not living with them, while only $52 \%$ of women report that this is the case for their partner. ${ }^{26}$ The summary statistics also indicate that more women are likely to be convinced that their male partners have other partners $(29 \%)$ than men $(27 \%)$. Under one half of both sexes report being certain that their partner has no other partners.

The picture is much the same when we consider the smaller sample of those with 1 partner only. A higher proportion of people indicate they are sure their partners have no other partners, while women are significantly more likely than men to report that they are sure their partner has other partners.

The last line of the table points to a factor which has not received much attention in the recent literature on HIV/AIDS information. $13 \%$ of last encounters for men involved one or both partners using alcohol, while $10 \%$ of last encounters for women involved alcohol. To the extent that alcohol interferes with rationality, messages learned through HIV information campaigns may be completely ineffective during encounters that involve alcohol. ${ }^{27}$

Table 6 reports the results of logit models of condom use. The dependent variable is whether a condom was used the last time the individual had sex with partner $j$, where a separate observation

\footnotetext{
${ }^{25}$ Calculating means at the level of the partnership implies that individuals with information on up to 3 recent partners in the last 12 months will be represented multiple times. For the sample of individuals reporting only 1 partner in the last year, the partnership and the individual are the same observation.

${ }^{26}$ The "partner is live out girl/boyfriend" category includes partner types described as "a casual acquaintance" and "a sex worker". We combined these categories with the "girl/boyfriend who does not live with me" group, as they contained a very small number of observations (265 and 13 respectively)

${ }^{27}$ For example, while there are hard-hitting and unavoidable billboards plastered around Gaborone advocating "Don't Drink and Drive" and "Always use condoms" messages, there do not appear to be messages of the "Don't drink and have sex" variety.
} 
is included for each of $J$ partners, for $\mathrm{J} \leq 3$. Controls for age cohort, own marital status, work status, and urban/rural residence are also included. Coefficients on these variables were sometimes significant, but are not reported both for brevity's sake and because the focus here is on the role of information and risk characteristics. The results are from a single model containing a full set of gender interaction terms. The baseline, or female coefficients are captured in the first column, and the male coefficients are the sum of these baseline coefficients and the interaction coefficients in the second column. The interaction coefficient is therefore the estimated difference in coefficients between men and women. Cell entries are the averages of estimated individual marginal effects.

Knowing that someone who looks healthy may be HIV-positive is associated with $5.7 \%$ higher probability of condom use for women, and men do not have a significantly or substantively different association. Knowing that condoms reduce the risk of HIV transmission is associated with a $10.6 \%$ higher probability of condom use for women. Men have a slightly higher probability of condom use if they know that condoms protect (13.8\%), but this difference is not statistically significant. None of the male interaction terms on the information variables shown here (or suppressed for brevity) were statistically significantly different from zero. This suggests that conditional on all other covariates, men who know the same types of HIV information as women have no higher probability of condom use.

Note that the coefficients on the HIV knowledge variables are all substantially larger than the coefficient on education. Each additional year of education is associated with a significant $1.7 \%$ increase in the likelihood of condom use for men and women. The results indicate that HIV-specific knowledge appears to be separately associated with reductions in risk-taking behavior.

To illustrate the combined effects of all of the male interaction terms, we present the information in the first two columns of Table 6 in graphical form. First, we predict the probability of condom use for each woman in the sample. Second, after setting each of the gender variables to 1 (e.g. as if male) for each woman and recreating each of the interaction terms for all the $\mathrm{X}$ variables, we generate a second set of predictions for each woman. This second prediction is constructed from the female distribution of covariates and the estimated coefficients for males. ${ }^{28}$ By conditioning on female X-characteristics in the first and second set of predictions, any differences between these two predictions reflect differences in predicted behavior for a man and a woman who have identical observable characteristics.

To get a sense of how different these two predictions are for all of the women in our sample (rather than looking at the average for the entire sample), we graph the results of this two-step exercise. In Figure 1, predicted values for condom use from the second step are plotted on the $\mathrm{Y}$ axis, against

\footnotetext{
${ }^{28}$ This is in the spirit of Oaxaca-Blinder wage decompositions as formalized for models with binary dependent variables in Fairlie (2006).
} 
predictions from step 1 on the $\mathrm{X}$-axis. The 45 degree line is the reference point. Note that the distribution of points lies largely above the 45 degree line. The Figure therefore indicates that, conditional on observables, most women would have had higher predicted probabilities of condom use at last sex if they had been behaving as men. ${ }^{29}$ The graph gives us a sense of how much of the difference between the male and female reports of condom use (0.708-0.625) is accounted for by differences in all of the male and female coefficients.

Figure 1 does not contain any measure of statistical precision. The precision underlying these results is a function of the standard errors on the vector of interaction terms. Going back to results in Table 6 , we find that although the full set of HIV information variables are jointly significantly different from zero, we cannot reject the null that the set of male interaction terms for these information variables are jointly zero. The test for whether the entire vector of male interaction coefficients is different from zero is soundly rejected at the $1 \%$ level. ${ }^{30}$ Hence, while there are differences in risky behavior between men and women, these difference are not the result of different responses to an individual's information set. And, as shown earlier, the information sets of men and women are themselves quite similar. Something other than information is driving the graph in Figure 1. In terms of our graph, this means that when predicted values of condom use lie above the 45 degree line, much of this gap is being generated by $\hat{\beta}^{\prime} s$ on the non-information $\mathrm{X}$-variables: own demographics and partner risk characteristics.

In the second panel of table 6 , we see how these own and partner characteristics are related to condom use at the margin. These results are suggestive of how people may be adapting their behaviors for different levels of perceived risk.

Women are $5.9 \%$ more likely to have used condoms at last sex if they have multiple partners. Men with multiple partners are significantly less likely to use condoms. Women are less likely to use condoms as the age gap between the respondent and her partner grows. This result is consistent with uneven bargaining power when the female is much younger than her partner. For both men and women, believing that one's partner may or does have other partners has a large and precise positive marginal associated with condom use: the likelihood of using a condom at last sex is between $4.7 \%$ (for women) and $11.5 \%$ (for men) higher when partners are suspected or known to not be monogamous, compared to when a partner is reportedly known to be monogamous. When the partner is known to not be monogamous, men are significantly more likely than women to report using a condom at last sex (the male interaction term on "Partner does have other partners" is large and significant at the $1 \%$ level). Again, this result is consistent with uneven bargaining power between sexes.

\footnotetext{
${ }^{29}$ A very similar graph delivers the same message for BAIS-1.

${ }^{30}$ The p-values for each of these three tests are reported in Table 6.
} 
Condom use is also significantly related to whether partners reside at home or elsewhere. A relationship in which one's partner lives at home may indicate a more stable relationship, or a one with lower monitoring costs. The base category is a marriage partner who lives at home. Relative to this category, individuals who have a girlfriend or boyfriend living at home are $11.7 \%$ more likely to use condoms at last sex. There is no difference in this association for men and women. Condom use is almost $20 \%$ higher (relative to when the partner is a spouse) when the partner does not live in the same residence. Again, this association is not different across men and women. That men and women are more likely to report condom use when their partnerships are more costly to monitor or less stable is an indication that each sex is perceiving increased HIV risk in these partnerships. However, it is of some concern that while women are more likely to report condom use when they know their partners have other partners, they are not as likely to do so as men. This is conditional on the levels of HIV knowledge, which start out being very similar across men and women.

The last result of the table is perhaps one of the most interesting. The correlation between alcohol consumption before sex and condom use is large, significant and striking. For individuals who report that one or other partner consumed alcohol before last sex are $8.8 \%$ less likely to use condom. The marginal impact of consuming alcohol about halves the increase in condom use associated with knowing that condoms reduce the risk of HIV/AIDS.

While it is certainly the case that our sample is a selected group (they have had sex before, they have had partners in the previous year, they agree to give information about partners), it is also true that the individuals in Tables 5 and 6 are apparently better informed than the overall sample. To investigate whether whether the logit results are being driven solely by the partnership information contained in observations with multiple partners, we restrict the sample to those with just one reported partnership in the last year. With this restriction, $20 \%$ of the male sample is lost and $8 \%$ of the female sample is lost. The results in the first three columns of Table 6 remain largely unaffected by this restriction.

There are two main differences. First, men in the single partner sample appear much more likely than women to report condom use at last sex if they know about MTC transmission. This may be because the type of man who has one partner is also the type of man more likely to have children with this partner and be exposed to relevant HIV information at family planning clinics and maternity wards. Second, men in the single partner sample are about $40 \%$ more likely to report condom use at last sex than women. This is conditional on HIV information and all of the risk characteristics. It is important to remember that the sample of individuals in this model does not cover each individual's entire sexual network- so we would not expect the reports of men and women to coincide exactly. However, it is difficult to explain why the coefficient on "male" in the restricted sample is so large and significant, without resorting to one of two explanations: either 
women prefer to not use condoms, or women are unable to bargain to as high a level of condom use as men. While there is a fertility motivation for the first story, the second story is also clearly plausible.

Our analysis illustrates a key empirical fact: In Botswana, a country with high seroprevalence rates and near universal awareness of HIV/AIDS, there are behavioral differences between men and women who have the same HIV information sets and the same level of education. Furthermore, not all of this gap can be explained away by differences in the distribution of risk characteristics, as the prediction exercise in Figure 1 (which holds the distribution of X's for women fixed) illustrates. It appears, as suggested by the paper's title, that education is not enough. There are aspects of gender that leave women more at risk.

\section{Conclusion}

It is certainly sensible to emphasize the importance of eliminating remaining information gaps between men and women in order to fight the spread of HIV/AIDS. However, our description of the situation in Botswana cautions against being overly optimistic about achieving an eradication of female vulnerability to the disease through this channel alone.

Using a rich set of individual-level data from Botswana, we show that men and women have very similar levels of HIV knowledge. For several types of questions, women actually report better knowledge than men. In comparison to many other African countries, the people of Botswana have extremely good information about HIV, although some gaps still remain in terms of misconceptions of transmission of the disease.

With simple logit models, we describe the relationship between one indicator of safer sex behavior (condom use at last sex), HIV information, partner characteristics and own demographics. These results indicate that individuals with specific risk factors for the disease- partners who reside elsewhere, partners who are not monogamous- are much more likely to use condoms. In comparing men and women, we show that even with the same distribution of characteristics, men are much more likely to use condoms at last sex. The message we take from this is that while individuals may have the same information about HIV methods of transmission and modes of protection, women may be unable to act on this knowledge to protect themselves against infection.

In the case of Botswana, it is not convincing to argue that sex-specific information gaps explain these differences in behavior. What drives these heterogeneities in behavior for men and women is an open question- one that is crucial for policy-makers to learn more about in order to evaluate expenditures on HIV education campaigns and to ascertain what complementary policies are 
necessary to successfully encourage risk-reducing sexual behaviors.

\section{References}

Coates, Thomas, The Voluntary HIV-1 Counseling, and Testing Efficacy Study Group, "Efficacy of Voluntary HIV-1 Counselling and Testing in Individuals and Couples in Kenya, Tanzania and Trinidad: a randomised trial," The Lancet, 2000, 356, 103-121.

Cohen, Barney, "The Emerging Fertility Transition in Sub-Saharan Africa," World Development, 1998, 26 (8), 1431-1461.

Fairlie, Robert, "An extension of the Blinder-Oaxaca decomposition technique to logit and probit models," January 2006. IZA Discussion Paper No, 1917.

Farmer, Paul, Women, Poverty, and AIDS: Sex, Drugs, and Structural Violence Series in Health and Social Justice, Common Courage Press, 1996.

Gersovitz, Mark, "The HIV Epidemic in four African Countries Seen Through The Demographic Health Surveys," Journal of African Economies, 2005, 14 (2), 191-246.

Glick, Peter and David E. Sahn, "Changes in HIV/AIDS Knowledge And Testing Behavior in Africa: How Much And For Whom?," 2005. Strategies And Analysis For Growth And Access (SAGA) Working Paper.

Heald, Suzette, "Abstain or Die: The development of HIV/AIDS policy in Botswana," Journal of Biosocial Science, November 2006, 38, 29-41.

Kamb, Mary L, Martin Fishbein, John M Douglas, and Fen Rhodes et al, "Efficacy of risk-reduction counseling to prevent human immunodeficiency virus," Journal of the American Medical Association, 1998, 289, 1161-1168.

Levinsohn, James and Justin McCrary, "HIV Seroprevalence in Botswana," 2006. Ford School of Public Policy, University of Michigan.

MacPhail, Catherine, B.G. Williams, and C. Campbell, "Relative Risk Of HIV infection among young men and women in a South African township," AIDS, 2002, 13, 331-342.

Martin, H. Gayle, "A Comparative Analysis of the Financing of HIV/AIDS Programmes in Botswana, Lesotho, Mozambique, South Africa, Swaziland and Zimbabwe," Technical Report, Human Sciences Research Council 2003. 
Nnko, S., JT Boerma, M. Urassa, G. Mwaluko, and B. Zaba, "Secretive females or swaggering males? An assessment of the quality of sexual partnership reporting in rural Tanzania," Social Science and Medicine, July 2004, 59 (2), 299-310.

Office, Central Statistics, "Botswana AIDS Impact Survey 2001,” Technical Report, Government of Botswana, Private Bag 0024, Gaberone, Botswana 2002.

UNAIDS, UNFPA and UNIFEM, "Women and HIV/AIDS: Confronting the crisis," Technical Report, UNAIDS 2004. 
Figure 1: Differences in predictions of condom use for women

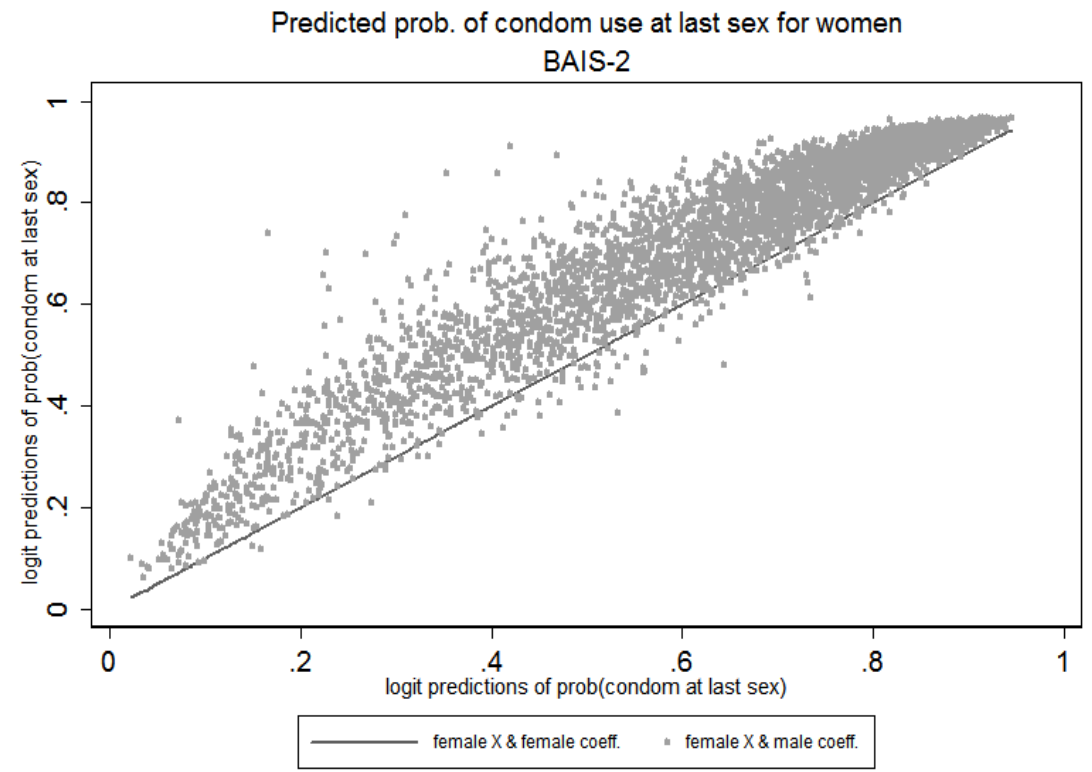

Graph shows predicted probabilities of condom use at last sex for women, given their own X-characteristics and male $\hat{\beta}^{\prime} s$ from the logit model of condom use at last sex. These logit model were run over the full sample of men and women in BAIS 2. The predictions are plotted on the y-axis against female predictions using female $\hat{\beta}^{\prime} s$ from the same logit model on the $\mathrm{x}$-axis. The 45 degree line is a reference point. 
Table 1: HIV knowledge in a selection of African countries (\%)

\begin{tabular}{|c|c|c|c|c|c|c|c|c|}
\hline Country & Group & $\begin{array}{l}\text { (1) Heard of } \\
\text { HIV? }\end{array}$ & $\begin{array}{ll}\text { (2) Less } & \text { risk } \\
\text { w. } & \text { con- } \\
\text { doms?** }^{* *} & \\
\end{array}$ & $\begin{array}{l}\text { (3) Less risk } \\
\text { being mono- } \\
\text { gamous?* }\end{array}$ & $\begin{array}{l}(4) \text { Healthy } \\
\text { person can be } \\
\text { HIV+? }\end{array}$ & $\begin{array}{l}\text { (5) Any risk } \\
\text { w. meal- } \\
\text { sharing? }\end{array}$ & $\begin{array}{l}(6) \quad \text { Any } \\
\text { risk w. } \\
\text { witchcraft? }\end{array}$ & (7) MTCT? \\
\hline Burkina & Urban men & 100 & 79 & 82 & 88 & 17 & 24 & 91 \\
\hline \multirow[t]{3}{*}{ Faso 2003} & Urban women & 99 & 70 & 80 & 80 & 27 & - & 82 \\
\hline & Rural men & 95 & 59 & 73 & 63 & 46 & 46 & 68 \\
\hline & Rural women & 95 & 42 & 58 & 48 & 70 & - & 55 \\
\hline Ghana & Urban men & 100 & 84 & 93 & 90 & 15 & 33 & 90 \\
\hline \multirow[t]{3}{*}{2003} & Urban women & 100 & 77 & 89 & 87 & 18 & 49 & 85 \\
\hline & Rural men & 99 & 80 & 88 & 83 & 33 & 47 & 82 \\
\hline & Rural women & 97 & 69 & 83 & 73 & 38 & 58 & 71 \\
\hline Kenya & Urban men & 100 & 79 & 92 & 93 & 12 & - & 93 \\
\hline \multirow[t]{3}{*}{2003} & Urban women & 99 & 69 & 85 & 91 & 19 & - & 91 \\
\hline & Rural men & 99 & 69 & 87 & 89 & 23 & - & 87 \\
\hline & Rural women & 98 & 58 & 79 & 83 & 32 & - & 86 \\
\hline Nigeria & Urban men & 99 & 68 & 82 & 80 & 34 & 43 & 67 \\
\hline \multirow[t]{3}{*}{2003} & Urban women & 95 & 58 & 73 & 69 & 41 & 49 & 66 \\
\hline & Rural men & 96 & 58 & 78 & 67 & 48 & 50 & 62 \\
\hline & Rural women & 82 & 38 & 53 & 45 & 62 & 66 & 45 \\
\hline Tanzania & Urban men & 100 & 74 & 91 & 92 & 12 & 10 & 91 \\
\hline \multirow[t]{3}{*}{2003} & Urban women & 100 & 72 & 89 & 88 & 16 & 15 & 93 \\
\hline & Rural men & 100 & 75 & 87 & 81 & 22 & 11 & 81 \\
\hline & Rural women & 99 & 65 & 85 & 73 & 28 & 19 & 79 \\
\hline Zambia & Urban men & 100 & 81 & 88 & 96 & - & - & 86 \\
\hline \multirow[t]{3}{*}{$2001 / 2002$} & Urban women & 99 & 80 & 89 & 96 & - & - & 90 \\
\hline & Rural men & 99 & 75 & 87 & 86 & - & - & 85 \\
\hline & Rural women & 96 & 66 & 82 & 78 & - & - & 83 \\
\hline
\end{tabular}

Summary statistics from MeasureDHS: HIV/AIDS Survey Indicators Database at http://www.measuredhs.com. Cells are sample \%'s of men/women (15-49 yrs) answering "yes" (columns 1,2,3,4,7) or "no" (columns 5,6). ** information for Zambia for this question taken from Table 1, Glick and Sahn (2005).

*In most surveys, question was about "being faithful to one partner", or "avoid multiple partners" or both. In (7), MTCT is Mother to Child transmission. 
Table 2: Descriptive statistics from BAIS 1 and BAIS 2

\begin{tabular}{|c|c|c|}
\hline & BAIS 1 & BAIS 2 \\
\hline \multicolumn{3}{|l|}{ Panel A: Entire sample } \\
\hline $\mathrm{N}$ observations & 7751 & 28200 \\
\hline $\mathrm{N}$ households & 1782 & 7594 \\
\hline \multirow{2}{*}{ Age } & 24.382 & 25.671 \\
\hline & $(19.738)$ & $(20.383)$ \\
\hline Age less than 10 & 0.266 & 0.258 \\
\hline Age 10 to 19 & 0.241 & 0.208 \\
\hline Age 20 to 29 & 0.177 & 0.191 \\
\hline Age 30 to 39 & 0.112 & 0.125 \\
\hline Age 40 to 49 & 0.079 & 0.082 \\
\hline Age 50 to 59 & 0.045 & 0.051 \\
\hline Age 60 years and above & 0.080 & 0.086 \\
\hline Male & 0.471 & 0.472 \\
\hline Urban area & 0.548 & 0.537 \\
\hline Resident of Gaborone & 0.097 & 0.100 \\
\hline \multirow[t]{2}{*}{ Hh size } & 4.454 & 3.736 \\
\hline & $(3.113)$ & $(2.823)$ \\
\hline \multicolumn{3}{|l|}{ Panel B: Subsample of adults } \\
\hline $\mathrm{N}$ observations & 3901 & 15150 \\
\hline \multirow[t]{2}{*}{ Age at first marriage } & 26.588 & 26.635 \\
\hline & $(7.731)$ & $(7.599)$ \\
\hline \multirow[t]{2}{*}{ Age at first sex* } & 18.967 & 18.459 \\
\hline & $(3.264)$ & $(4.037)$ \\
\hline Married/living together & 0.451 & 0.490 \\
\hline Divorced/separated & 0.026 & 0.028 \\
\hline Widow & 0.077 & 0.075 \\
\hline Never married/never living together & 0.45 & 0.41 \\
\hline \multirow[t]{2}{*}{ Years of education } & 8.360 & 8.964 \\
\hline & $(3.450)$ & $(3.561)$ \\
\hline Non-formal education & 0.022 & 0.013 \\
\hline Primary education & 0.408 & 0.339 \\
\hline Secondary education & 0.436 & 0.454 \\
\hline Tertiary education & 0.133 & 0.195 \\
\hline Respondent can read easily & 0.672 & 0.666 \\
\hline
\end{tabular}

Notes:Summary statistics are presented as weighted means or proportions. Standard deviations for continuous variables in parentheses. Statistics in Panel A are calculated on the full sample of individuals, while statistics in Panel B are calculated over the subset of individuals at least 20 yrs old. $*$ is only calculated over the subset of individuals who consented to answered this question in the individual level survey: 2195 in BAIS-1 and 9340 in BAIS-2 
Table 3: Share of sample with knowledge of HIV risks and prevention methods

\begin{tabular}{|c|c|c|c|c|c|c|c|c|}
\hline Group & Wave & $\begin{array}{l}\text { (1) Ever heard of } \\
\text { HIV? }\end{array}$ & $\begin{array}{l}\text { (2)Condoms re- } \\
\text { duce risk? }\end{array}$ & $\begin{array}{l}\text { (3) Monogamy } \\
\text { reduces risk? }\end{array}$ & $\begin{array}{l}\text { (4)Healthy } \\
\text { person can be } \\
\text { HIV+? }\end{array}$ & $\begin{array}{l}\text { (5) Get HIV by } \\
\text { sharing meals? }\end{array}$ & $\begin{array}{l}\text { (6) Get HIV by } \\
\text { witchcraft? }\end{array}$ & $\begin{array}{l}\text { (7) Mother can } \\
\text { pass HIV to } \\
\text { child? } \\
\end{array}$ \\
\hline Urban & BAIS-1 & 0.96 & 0.89 & 0.84 & 0.78 & 0.41 & 0.23 & 0.88 \\
\hline \multirow[t]{3}{*}{ Women } & & 1,121 & 1074 & 1,083 & 1,083 & 1,080 & 1,082 & 1,083 \\
\hline & BAIS-2 & 0.95 & 0.88 & 0.86 & 0.85 & 0.32 & 0.21 & 0.91 \\
\hline & & 4,987 & 4,760 & 4,748 & 4,761 & 4,753 & 4,756 & 4,758 \\
\hline Urban & BAIS-1 & 0.94 & 0.88 & 0.84 & 0.77 & 0.45 & 0.27 & 0.83 \\
\hline \multirow[t]{3}{*}{ Men } & & 933 & 878 & 880 & 881 & 879 & 881 & 881 \\
\hline & BAIS-2 & 0.96 & 0.89 & 0.86 & 0.86 & 0.36 & 0.22 & 0.86 \\
\hline & & 4,120 & 3,951 & 3,946 & 3,952 & 3,942 & 3,942 & 3,944 \\
\hline Rural & BAIS-1 & 0.94 & 0.87 & 0.85 & 0.67 & 0.45 & 0.26 & 0.81 \\
\hline \multirow[t]{3}{*}{ Women } & & 1,016 & 953 & 952 & 953 & 952 & 953 & 952 \\
\hline & BAIS-2 & 0.91 & 0.83 & 0.82 & 0.77 & 0.48 & 0.30 & 0.87 \\
\hline & & 3,048 & 2,771 & 2,771 & 2,774 & 2,767 & 2,767 & 2,772 \\
\hline Rural & BAIS-1 & 0.90 & 0.86 & 0.83 & 0.64 & 0.53 & 0.29 & 0.73 \\
\hline \multirow[t]{3}{*}{ Men } & & 862 & 776 & 774 & 777 & 775 & 776 & 776 \\
\hline & BAIS-2 & 0.90 & 0.81 & 0.82 & 0.72 & 0.55 & 0.30 & 0.78 \\
\hline & & 2,594 & 2,309 & 2,308 & 2,313 & 2,310 & 2,308 & 2,310 \\
\hline \multirow[t]{4}{*}{ All } & BAIS-1 & 0.938 & 0.877 & 0.838 & 0.726 & 0.452 & 0.257 & 0.822 \\
\hline & & 3,932 & 3,681 & 3,689 & 3,694 & 3,686 & 3,692 & 3,692 \\
\hline & BAIS-2 & 0.933 & 0.859 & 0.844 & 0.813 & 0.406 & 0.251 & 0.865 \\
\hline & & 14,749 & 13,791 & 13,773 & 13,800 & 13,772 & 13,773 & 13,784 \\
\hline Sig. diff. & ver time? & no & yes & no & yes & yes & no & yes \\
\hline
\end{tabular}

Notes: Each subgroup-variable cell contains the person weighted mean and total responses to questions with YES/NO (question (1)) or

YES/NO/DNK (all other questions) responses. (1)-(4) and (7) are coded as 1 for a YES response; (5) and (6) are coded as 1 for a YES or DNK response.

The significant difference over time is at the $1 \%$ level. 
Table 4: Logits of selected HIV information questions

\begin{tabular}{|c|c|c|c|c|c|c|c|c|}
\hline Variable & $\begin{array}{l}\text { (1) Ever heard of } \\
\text { HIV? }\end{array}$ & $\begin{array}{l}\text { (2)Reduce } \\
\text { risk using } \\
\text { condoms? }^{a}\end{array}$ & $\begin{array}{lr}(3) & \text { Reduce } \\
\text { risk } & \text { being } \\
\text { monogamous }^{a}\end{array}$ & $\begin{array}{l}(4) \\
\text { person } \\
\operatorname{HIV}_{+}{ }^{a}\end{array}$ & $\begin{array}{l}\text { Healthy } \\
\text { can be }\end{array}$ & $\begin{array}{l}\text { (5) HIV risk in } \\
\text { meal-sharing? }\end{array}$ & $\begin{array}{l}(6) \text { HIV } \\
\text { risk through } \\
\text { witchcraft? }^{b}\end{array}$ & (7) MTCT? ${ }^{a}$ \\
\hline Male & $\begin{array}{l}\mathbf{0 . 0 2 8} \\
(0.011)\end{array}$ & $\begin{array}{l}0.005 \\
(0.019)\end{array}$ & $\begin{array}{l}0.003 \\
(0.022)\end{array}$ & $\begin{array}{l}-0.012 \\
(0.020)\end{array}$ & & $\begin{array}{l}\mathbf{0 . 0 6 0} \\
(0.029)\end{array}$ & $\begin{array}{l}-0.004 \\
(0.025)\end{array}$ & $\begin{array}{l}-\mathbf{0 . 0 4 4} \\
(0.018)\end{array}$ \\
\hline Age 20 to 29 & $\begin{array}{l}\mathbf{0 . 0 3 5} \\
(0.010)\end{array}$ & $\begin{array}{l}\mathbf{0 . 0 5 0} \\
(0.013)\end{array}$ & $\begin{array}{l}\mathbf{0 . 0 4 6} \\
(0.013)\end{array}$ & $\begin{array}{l}\mathbf{0 . 0 6 9} \\
(0.013)\end{array}$ & & $\begin{array}{l}0.011 \\
(0.017)\end{array}$ & $\begin{array}{l}0.015 \\
(0.015)\end{array}$ & $\begin{array}{l}\mathbf{0 . 0 6 0} \\
(0.014)\end{array}$ \\
\hline Age 30 to 39 & $\begin{array}{l}\mathbf{0 . 0 7 6} \\
(0.012)\end{array}$ & $\begin{array}{l}\mathbf{0 . 0 5 6} \\
(0.014)\end{array}$ & $\begin{array}{l}\mathbf{0 . 0 6 2} \\
(0.016)\end{array}$ & $\begin{array}{l}\mathbf{0 . 0 6 9} \\
(0.015)\end{array}$ & & $\begin{array}{l}0.038 \\
(0.020)\end{array}$ & $\begin{array}{l}\mathbf{0 . 0 4 2} \\
(0.018)\end{array}$ & $\begin{array}{l}\mathbf{0 . 0 6 7} \\
(0.015)\end{array}$ \\
\hline Age 40 to 49 & $\begin{array}{l}\mathbf{0 . 0 8 4} \\
(0.015)\end{array}$ & $\begin{array}{l}\mathbf{0 . 0 5 5} \\
(0.016)\end{array}$ & $\begin{array}{l}\mathbf{0 . 0 9 6} \\
(0.019)\end{array}$ & $\begin{array}{l}\mathbf{0 . 1 1 4} \\
(0.019)\end{array}$ & & $\begin{array}{l}0.037 \\
(0.022)\end{array}$ & $\begin{array}{l}\mathbf{0 . 0 4 0} \\
(0.020)\end{array}$ & $\begin{array}{l}\mathbf{0 . 0 8 1} \\
(0.017)\end{array}$ \\
\hline Age 50 and above & $\begin{array}{l}\mathbf{0 . 1 1 0} \\
(0.017)\end{array}$ & $\begin{array}{l}0.031 \\
(0.017)\end{array}$ & $\begin{array}{l}\mathbf{0 . 0 8 2} \\
(0.020)\end{array}$ & $\begin{array}{l}\mathbf{0 . 1 0 0} \\
(0.020)\end{array}$ & & $\begin{array}{l}\mathbf{0 . 0 7 2} \\
(0.026)\end{array}$ & $\begin{array}{l}0.000 \\
(0.024)\end{array}$ & $\begin{array}{l}\mathbf{0 . 0 8 4} \\
(0.018)\end{array}$ \\
\hline Male*age 20 to 29 & $\begin{array}{l}0.001 \\
(0.015)\end{array}$ & $\begin{array}{r}\mathbf{- 0 . 0 4 6} \\
(0.019)\end{array}$ & $\begin{array}{l}-0.002 \\
(0.020)\end{array}$ & $\begin{array}{l}-0.008 \\
(0.022)\end{array}$ & & $\begin{array}{l}0.016 \\
(0.026)\end{array}$ & $\begin{array}{l}-0.027 \\
(0.024)\end{array}$ & $\begin{array}{l}-0.022 \\
(0.019)\end{array}$ \\
\hline Male*age 30 to 39 & $\begin{array}{l}-0.030 \\
(0.018)\end{array}$ & $\begin{array}{r}\mathbf{- 0 . 0 6 5} \\
(0.023)\end{array}$ & $\begin{array}{l}-0.010 \\
(0.025)\end{array}$ & $\begin{array}{l}0.031 \\
(0.027)\end{array}$ & & $\begin{array}{l}0.008 \\
(0.032)\end{array}$ & $\begin{array}{l}-0.031 \\
(0.029)\end{array}$ & $\begin{array}{l}-0.040 \\
(0.021)\end{array}$ \\
\hline Male*age 40 to 49 & $\begin{array}{l}-0.028 \\
(0.024)\end{array}$ & $\begin{array}{l}-0.051 \\
(0.027)\end{array}$ & $\begin{array}{l}-0.020 \\
(0.030)\end{array}$ & $\begin{array}{l}-0.025 \\
(0.033)\end{array}$ & & $\begin{array}{l}0.044 \\
(0.037)\end{array}$ & $\begin{array}{l}-0.031 \\
(0.034)\end{array}$ & $\begin{array}{l}-0.032 \\
(0.026)\end{array}$ \\
\hline Male*age 50 up & $\begin{array}{l}-0.022 \\
(0.027)\end{array}$ & $\begin{array}{l}-0.051 \\
(0.029)\end{array}$ & $\begin{array}{l}0.036 \\
(0.036)\end{array}$ & $\begin{array}{l}-0.020 \\
(0.036)\end{array}$ & & $\begin{array}{l}-0.028 \\
(0.045)\end{array}$ & $\begin{array}{l}-0.016 \\
(0.039)\end{array}$ & $\begin{array}{l}-0.015 \\
(0.028)\end{array}$ \\
\hline
\end{tabular}


Table 4 (continued): Logits of selected HIV information questions

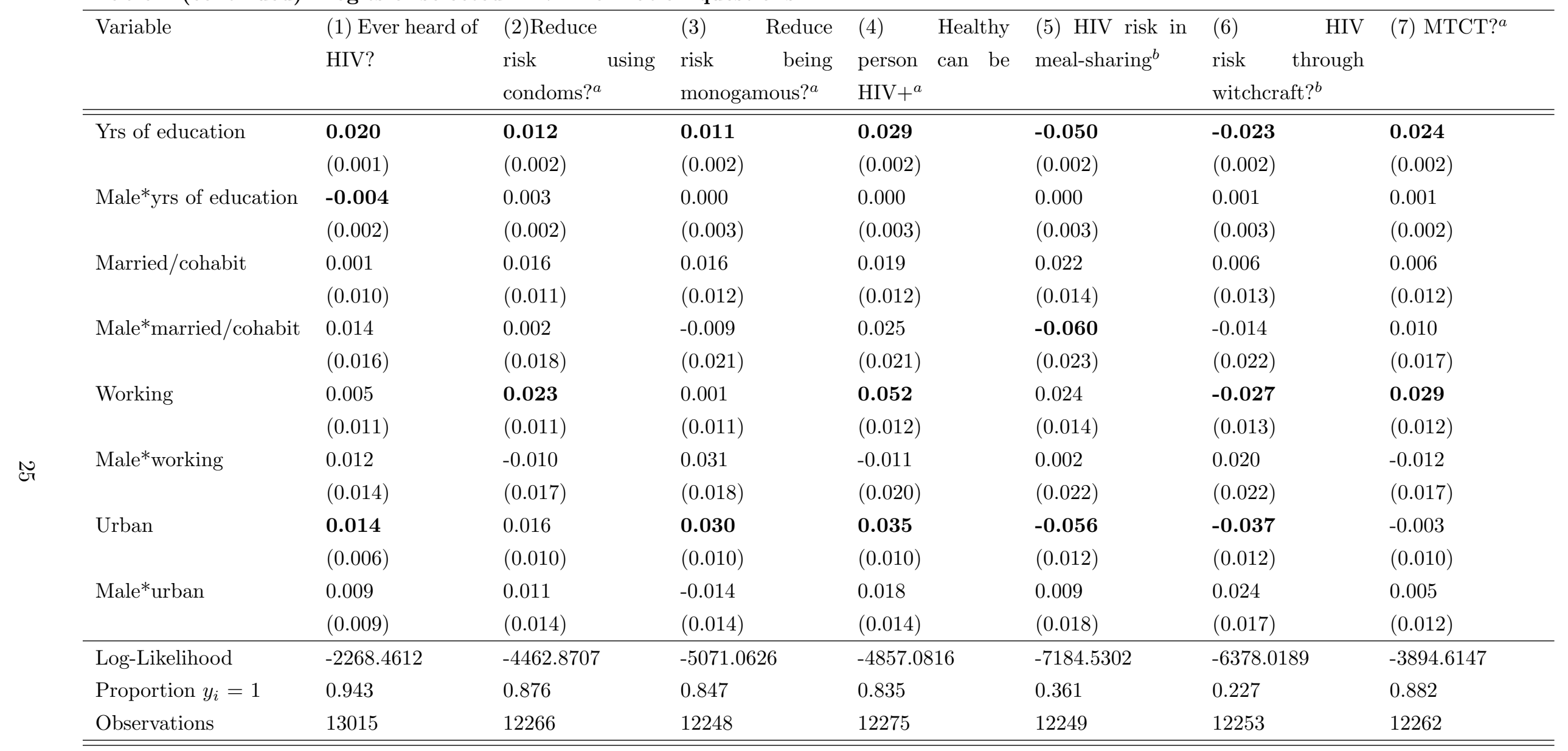

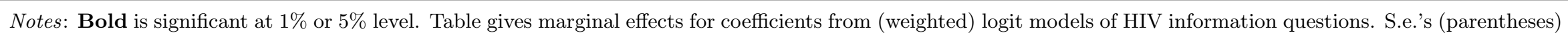

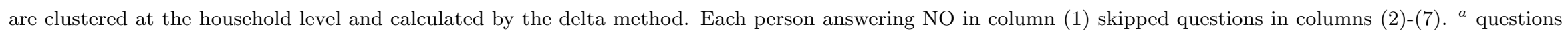

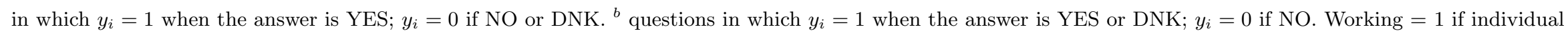

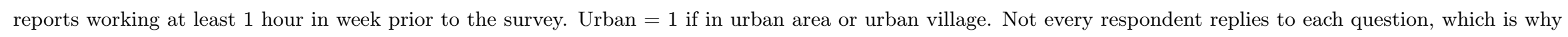
the total $\mathrm{N}$ changes in each column. 
Table 5 : Means of sexual risk behavior variables, own and partner characteristics

\begin{tabular}{|c|c|c|c|c|c|c|}
\hline \multirow[b]{2}{*}{ BAIS-2 } & \multicolumn{2}{|c|}{ Full sample } & \multirow[b]{2}{*}{ sig. dif? } & \multicolumn{3}{|c|}{ Sample w. 1 partner } \\
\hline & Men & Women & & Men & Women & sig. dif? \\
\hline \multicolumn{7}{|l|}{ Risk behaviors } \\
\hline num. partners last yr (if $>0$ ) & $\begin{array}{l}1.395 \\
(0.023)\end{array}$ & $\begin{array}{l}1.109 \\
(0.009)\end{array}$ & $\mathrm{y}$ & - & - & \\
\hline \multirow[t]{2}{*}{ condom use first sex* } & 0.729 & 0.658 & $\mathrm{y}$ & 0.674 & 0.630 & $\mathrm{y}$ \\
\hline & $(0.006)$ & $(0.007)$ & & $(0.009)$ & $(0.007)$ & \\
\hline \multirow[t]{2}{*}{ condom use last sex* } & 0.708 & 0.625 & $\mathrm{y}$ & 0.644 & 0.595 & $\mathrm{y}$ \\
\hline & $(0.007)$ & $(0.007)$ & & $(0.009)$ & $(0.007)$ & \\
\hline \multicolumn{7}{|l|}{ Individual HIV knowledge } \\
\hline \multirow[t]{2}{*}{ Had HIV info recently? } & 0.746 & 0.703 & $\mathrm{y}$ & 0.745 & 0.703 & $\mathrm{y}$ \\
\hline & $(0.007)$ & $(0.007)$ & & $(0.008)$ & $(0.007)$ & \\
\hline \multirow[t]{2}{*}{ Can condoms protect? } & 0.914 & 0.917 & $\mathrm{n}$ & 0.911 & 0.915 & $\mathrm{n}$ \\
\hline & $(0.005)$ & $(0.004)$ & & $(0.005)$ & $(0.004)$ & \\
\hline \multirow[t]{2}{*}{ Can monogamy protect? } & 0.890 & 0.881 & $\mathrm{n}$ & 0.899 & 0.883 & $\mathrm{y}(5 \%)$ \\
\hline & $(0.005)$ & $(0.005)$ & & $(0.006)$ & $(0.005)$ & \\
\hline \multirow[t]{2}{*}{ Can healthy person be HIV+? } & 0.902 & 0.881 & $\mathrm{y}$ & 0.902 & 0.879 & $\mathrm{y}$ \\
\hline & $(0.005)$ & $(0.005)$ & & $(0.005)$ & $(0.005)$ & \\
\hline \multirow[t]{2}{*}{ Can HIV be transmitted by mosquitos? } & 0.440 & 0.459 & $\mathrm{n}$ & 0.435 & 0.456 & $\mathrm{n}$ \\
\hline & $(0.008)$ & $(0.007)$ & & $(0.009)$ & $(0.007)$ & \\
\hline \multirow[t]{2}{*}{ Can HIV be transmitted by meals? } & 0.362 & 0.326 & $\mathrm{y}$ & 0.361 & 0.328 & $\mathrm{y}$ \\
\hline & $(0.008)$ & $(0.007)$ & & $(0.009)$ & $(0.007)$ & \\
\hline \multirow[t]{2}{*}{ Can HIV be transmitted by witchcraft? } & 0.203 & 0.212 & $\mathrm{n}$ & 0.205 & 0.215 & $\mathrm{n}$ \\
\hline & $(0.007)$ & $(0.006)$ & & $(0.007)$ & $(0.006)$ & \\
\hline \multirow[t]{2}{*}{ Can HIV be transmitted MTC? } & 0.905 & 0.941 & $\mathrm{y}$ & 0.904 & 0.940 & $\mathrm{y}$ \\
\hline & $(0.005)$ & $(0.003)$ & & $(0.005)$ & $(0.004)$ & \\
\hline
\end{tabular}


Table 5 (contd): Means of sexual risk behavior variables, own and partner characteristics

\begin{tabular}{|c|c|c|c|c|c|c|}
\hline \multirow[b]{2}{*}{ BAIS-2 } & \multicolumn{2}{|c|}{ Full sample } & \multirow[b]{2}{*}{ sig. dif? } & \multicolumn{3}{|c|}{ Sample w. 1 partner } \\
\hline & Men & Women & & Men & Women & sig. dif? \\
\hline \multicolumn{7}{|l|}{ Own/partner characteristics } \\
\hline \multirow[t]{2}{*}{ multiple partners? } & 0.193 & 0.078 & $\mathrm{y}$ & - & - & \\
\hline & $(0.006)$ & $(0.004)$ & & & & \\
\hline \multirow[t]{2}{*}{ average age gap* } & 4.930 & 6.011 & $\mathrm{y}$ & 5.012 & 6.058 & $\mathrm{y}$ \\
\hline & $(0.080)$ & $(0.079)$ & & $(0.096)$ & $(0.086)$ & \\
\hline \multirow[t]{2}{*}{ partner $=$ live in spouse ${ }^{*}$} & 0.189 & 0.223 & $\mathrm{y}$ & 0.267 & 0.256 & $\mathrm{n}$ \\
\hline & $(0.006)$ & $(0.006)$ & & $(0.008)$ & $(0.007)$ & \\
\hline \multirow[t]{2}{*}{ partner=live in girl/boy friend* } & 0.198 & 0.254 & $\mathrm{y}$ & 0.256 & 0.278 & $\mathrm{y}(5 \%)$ \\
\hline & $(0.006)$ & $(0.006)$ & & $(0.008)$ & $(0.007)$ & \\
\hline \multirow[t]{2}{*}{ partner=live out girl/boy friend* } & 0.613 & 0.523 & $\mathrm{y}$ & 0.476 & 0.466 & $\mathrm{n}$ \\
\hline & $(0.007)$ & $(0.007)$ & & $(0.009)$ & $(0.007)$ & \\
\hline \multirow[t]{2}{*}{ partner has no other partners* } & 0.484 & 0.443 & $\mathrm{y}$ & 0.599 & 0.485 & $\mathrm{y}$ \\
\hline & $(0.007)$ & $(0.007)$ & & $(0.009)$ & $(0.007)$ & \\
\hline \multirow[t]{2}{*}{ partner may have other partners* } & 0.242 & 0.269 & $\mathrm{y}$ & 0.255 & 0.280 & $\mathrm{y}(5 \%)$ \\
\hline & $(0.006)$ & $(0.006)$ & & $(0.008)$ & $(0.007)$ & \\
\hline \multirow[t]{2}{*}{ partner does have other partners* } & 0.274 & 0.288 & $\mathrm{n}$ & 0.147 & 0.235 & $\mathrm{y}$ \\
\hline & $(0.006)$ & $(0.006)$ & & $(0.006)$ & $(0.006)$ & \\
\hline \multirow[t]{2}{*}{ partner/self took alcohol last sex* } & 0.132 & 0.104 & $\mathrm{y}$ & 0.097 & 0.090 & $\mathrm{n}$ \\
\hline & $(0.005)$ & $(0.004)$ & & $(0.005)$ & $(0.004)$ & \\
\hline n (partnerships) & 3729 & 4251 & & 2459 & 3624 & \\
\hline n (individuals) & 3055 & 3948 & & 2459 & 3624 & \\
\hline
\end{tabular}

Notes:(*) means calculated over total partnerships (up to three recent partnerships for each individual). The smaller sample of individuals reporting 1 recent sex partner and information on only 1 recent partnership excludes anyone with data on multiple partnerships (785) or reporting more than one recent sex partner (an additional 135 people). The "dif" column indicates whether difference in means across men and women is significantly different from 0 , at the $1 \%$ (or $5 \%$ ) level. 
Table 6: Relationship between HIV relevant information and condom use at last sex: marginal effects for BAIS-2

\begin{tabular}{|c|c|c|c|c|}
\hline & \multicolumn{2}{|c|}{ Full sample } & \multicolumn{2}{|c|}{ Sample with only 1 partner } \\
\hline & Female $\hat{\beta}$ 's & $\begin{array}{l}\text { Male interac- } \\
\text { tions }\end{array}$ & Female $\hat{\beta}$ 's & $\begin{array}{l}\text { Male interac- } \\
\text { tions }\end{array}$ \\
\hline \multicolumn{5}{|l|}{ Information variables } \\
\hline \multirow[t]{2}{*}{ Can healthy person be HIV+? } & 0.057 & -0.002 & 0.050 & -0.025 \\
\hline & $(0.022)$ & $(0.037)$ & $(0.024)$ & $(0.042)$ \\
\hline \multirow[t]{2}{*}{ Can condoms reduce risk? } & 0.106 & 0.032 & 0.124 & 0.035 \\
\hline & $(0.022)$ & $(0.036)$ & $(0.026)$ & $(0.041)$ \\
\hline Can HIV/AIDS be transmitted & -0.002 & 0.063 & -0.018 & 0.112 \\
\hline from mother to child? & $(0.029)$ & $(0.041)$ & $(0.030)$ & $(0.048)$ \\
\hline \multicolumn{5}{|l|}{ Demographics } \\
\hline \multirow[t]{2}{*}{ Gender } & - & 0.124 & - & 0.402 \\
\hline & & $(0.100)$ & & $(0.151)$ \\
\hline \multirow[t]{2}{*}{ Years of education } & 0.017 & 0.000 & 0.017 & -0.004 \\
\hline & $(0.003)$ & $(0.004)$ & $(0.003)$ & $(0.004)$ \\
\hline \multicolumn{5}{|l|}{ Own and partner risk characteristics } \\
\hline \multirow[t]{2}{*}{ Individual has multiple partners ${ }^{a}$} & 0.059 & -0.064 & - & \\
\hline & $(0.023)$ & $(0.031)$ & & \\
\hline \multirow[t]{2}{*}{ Age gap between partners } & -0.004 & 0.004 & -0.004 & 0.004 \\
\hline & $(0.001)$ & $(0.002)$ & $(0.001)$ & $(0.002)$ \\
\hline \multirow[t]{2}{*}{ Partner may have other partners } & 0.046 & 0.016 & 0.050 & 0.019 \\
\hline & $(0.016)$ & $(0.025)$ & $(0.018)$ & $(0.029)$ \\
\hline \multirow[t]{2}{*}{ Partner does have other partners } & 0.043 & 0.072 & 0.044 & 0.073 \\
\hline & $(0.017)$ & $(0.029)$ & $(0.020)$ & $(0.038)$ \\
\hline \multirow[t]{2}{*}{ Partner is live in girl/boy friend } & 0.117 & 0.002 & 0.125 & -0.020 \\
\hline & $(0.019)$ & $(0.027)$ & $(0.021)$ & $(0.030)$ \\
\hline \multirow[t]{2}{*}{ Partner is live out girl/boy friend } & 0.194 & 0.068 & 0.186 & -0.021 \\
\hline & $(0.028)$ & $(0.042)$ & $(0.034)$ & $(0.053)$ \\
\hline \multirow[t]{2}{*}{ One/both had alcohol before $\operatorname{sex}^{b}$} & -0.088 & -0.030 & -0.092 & -0.044 \\
\hline & $(0.021)$ & $(0.031)$ & $(0.025)$ & $(0.040)$ \\
\hline Log likelihood & \multicolumn{2}{|c|}{-4105.208} & \multicolumn{2}{|c|}{-3322.743} \\
\hline chi(2) test - baseline info coeff* & \multicolumn{2}{|c|}{38.255} & \multicolumn{2}{|c|}{38.386} \\
\hline chi(2) test - info interaction coeff* & \multicolumn{2}{|c|}{5.460} & \multicolumn{2}{|c|}{9.470} \\
\hline chi(2) test - all interaction coeff* & \multicolumn{2}{|c|}{50.311} & \multicolumn{2}{|c|}{22.595} \\
\hline Observations & \multicolumn{2}{|c|}{7980} & \multicolumn{2}{|c|}{6083} \\
\hline
\end{tabular}


Notes: Table gives sample averages of individual marginal effects from logit models, weighted by person weight. Standard errors (parentheses) are calculated by the delta method and clustered at the household level to account for multiple observations in each household. $y_{i j}=1$ if condom used by person $\mathrm{i}$ at last sex with partner $\mathrm{j}$. Columns (1) and (2) include individuals reporting at least 1 partner in the last year and who have information on all of the $\mathrm{X}$-variable; columns (3) and (4) restrict to those with only 1 partner in last year. Omitted are coefficients on some of the information variables (recent info, mosquitos, witchcraft, sharing meals), age group, marital status, working status and urban residence. ${ }^{a}$ is indicator for a person who has more than one partner in past year; ${ }^{b}$ indicates that one or both partners drank alcohol before first/last sex. Bolded coefficients are significant at $5 \%$ or $1 \%$ level. *denotes p-value of chi(2) tests for joint significance of alternate sets of variables. 


\section{Appendix: Questions from BAIS-1 and BAIS-2 surveys}

\section{HIV information questions}

Where questions differ, both versions are presented.

- Have you ever heard of the virus HIV or an illness called AIDS? (Y/N)

- In the past 4 weeks, have you heard or seen any information about the HIV/AIDS? (Y/N)

- Can people reduce their chances of getting HIV/AIDS by using a condom correctly every time they have sex? $(\mathrm{Y} / \mathrm{N} / \mathrm{DNK})^{*}$

- Do you think that a person can get infected with HIV/AIDS through mosquito bites? (Y/N/DNK) Can a person get infected with HIV/AIDS by sharing a meal with a person who has HIV/AIDS? $(\mathrm{Y} / \mathrm{N} / \mathrm{DNK})$

- Can people get HIV/AIDS because of witchcraft? (Y/N/DNK)

- Can HIV/AIDS be transmitted from a mother to a child? (Y/N/DNK)

- Can people reduce their chances of getting HIV/AIDS by having only one sex partner who has no other partners? (Y/N/DNK) - BAIS-1. Can people reduce their chances of getting HIV/AIDS by having only one uninfected sex partner who has no other partners? (Y/N/DNK) - BAIS-2

- Can a person who looks healthy be infected with HIV/AIDS? (Y/N/DNK)- BAIS-1. Is it possible for a healthy looking person to have the AIDS virus? - BAIS-2.

\section{Questions about sexual partners}

- In the last 12 months with how many people overall have you had sex (including these last partners we've discussed)? (number)

- What is your relationship to [most recent/next most recent partner]? (Husband/wife, live-in partner, girlfriend/boyfriend not living with you, someone you paid for sex or who paid you for sex, casual acquaintance)

- How old is this partner? (if don’t know exact age, probe for approximate age.)

- Did you use a condom the first time you had sex with this partner? (Y/N/Do not recall)

- Did you use a condom the last time you had sex with this partner? (Y/N/Do not recall)

- Do you think this partner has other partners? (Y/N/DNK)

- The last time you had sex, did you or this partner drink alcohol? (Y/N/DNK) - BAIS-1. The last time you had sexual intercourse, had you taken an alcoholic drink? (Y/N/DNK) - BAIS-2 Last time you had sexual intercourse, had your partner taken an alcoholic drink? (Y/N/DNK) - BAIS-2

Note: *respondents were also coded as "Yes" if they answered "Use Condoms" to an earlier question, "What can a person do to reduce the risk of being infected with HIV?" 